\title{
The importance of resource security for poverty eradication
}

\author{
Mathis Wackernagel $\oplus^{1 凶}$, Laurel Hanscom', Priyangi Jayasinghe², David Lin', Adeline Murthy', \\ Evan Neill ${ }^{3}$ and Peter Raven ${ }^{4}$
}

\begin{abstract}
As humanity's demand on natural resources is increasingly exceeding Earth's biological rate of regeneration, environmental deterioration such as greenhouse gas accumulation in the atmosphere, ocean acidification and groundwater depletion is accelerating. As a result, the capacity of ecosystems to renew biomass, herein referred to as 'biocapacity', is becoming the material bottleneck for the human economy. Yet, economic development theory and practice continue to underplay the importance of natural resources, most notably biological ones. We analysed the unequal exposure of national economies to biocapacity constraints. We found that a growing number of people live in countries with both biocapacity deficits and below-average income. Low income thwarts these economies' ability to compete for needed resources on the global market. By $2017, \mathbf{7 2} \%$ of humanity lived in such countries. This trend not only erodes their possibilities for maintaining progress but also eliminates their chances for eradicating poverty, a situation we call an 'ecological poverty trap'.
\end{abstract}

T his paper strengthens the case that biological resource security is a far more influential factor contributing to lasting development success than most economic development theories and practices would suggest and shows how unevenly it affects distinct human populations.

A fundamental ecological concept posits that net primary productivity of ecosystems is the basis of all life. Therefore, we investigate how biological resource scarcity can limit economic development as those resources are under increasing threat ${ }^{1-3}$. We define 'biological resource security' as the ability of a population to secure access to their current level of biological resource demand, or a higher one if the current level does not allow them to meet their material needs.

Not only people, but all life, depend on a material metabolism. To secure their metabolism, people compete with other living things for the biological productivity of ecosystems. The metabolism encompasses basic life-support functions, including food, clean water, waste absorption and shelter. While this has always been the case, the Anthropocene epoch has marked a new era characterized by Homo sapiens' global dominance. Within this new context, conservative estimates indicate that in 2020, the demand of biological resources of all people combined exceeded the amount Earth's ecosystems produce by at least $56 \%{ }^{4}$. Given this massive overuse, also called ecological overshoot, biological resource security is no longer guaranteed, making biological productivity, our planet's capacity to regenerate biomass, a material bottleneck for the human economy ${ }^{1,2}$.

Overuse is by definition a time-limited condition-it cannot go on forever ${ }^{3,5-7}$. Thus, global ecological overshoot erodes biological resource sustainability and, therefore, security. Paradoxically, because of accumulated resource stocks, it has still been possible for humanity, even during the past decades of global ecological overshoot, to continuously increase total demand ${ }^{8,9}$. Increased overshoot has accelerated the depletion of the biosphere's ecological assets, resulting in increased biodiversity loss ${ }^{10-12}$, climate change ${ }^{13}$, forest destruction ${ }^{14}$ and freshwater scarcity ${ }^{15}$. Delayed impact and weak feedback amplify future resource security challenges by further depleting natural capital.
Some may perceive that economic impacts of such depletion occur far in the future. Indeed, it is unknown how long people can overuse natural capital before economic performance is measurably affected. Therefore, the time span for which ecological overuse can persist is a critical parameter, as it defines the maximum transition time to a regenerative future, when (a possibly diminished) biological regeneration will constrict humanity's material metabolism.

There may not be a precise answer for how long overuse can persist as time constants for each biological asset vary. For example, a forest that matured over 50 years, whose trees are harvested at the rate of $2 \%$ per year, would be left with no mature tree within 25 years. Groundwater and freshwater lakes can be radically diminished within decades, as has happened in many places, from Lake Chad to Lake Aral, the Ogallala Aquifer and the California Central Valley. Overfishing has led to fisheries collapse ${ }^{16}$, and carbon emissions from fossil fuel combustion have contributed to an accumulation of atmospheric greenhouse gases. Concentrations have increased from $280 \mathrm{ppm} \mathrm{CO}_{2}$-equivalent $\left(\mathrm{CO}_{2} \mathrm{e}\right)$ before the industrial revolution in 1750 to over $500 \mathrm{ppm} \mathrm{CO}_{2} \mathrm{e}$ as of $2019^{17}$. The current concentration is higher than the $450 \mathrm{ppm} \mathrm{CO}_{2}$ e needed to have a moderate chance of limiting global average warming less than $2{ }^{\circ} \mathrm{C}$ above pre-industrial levels, according to the Intergovernmental Panel on Climate Change ${ }^{18}$. This means that the atmospheric carbon sink limits associated with a stable climate have already been breached, even though the effects have not yet fully played out. Avoiding the threat of an unstable climate would require rapidly eliminating the use of fossil fuels, which now provide $80 \%$ of humanity's commercial energy use ${ }^{19}$. It would also necessitate additional carbon sequestration.

Accordingly, the impacts of biological overuse are not only already present, but also have, in some domains, exceeded the tolerable margins. Other domains may be breached within decades, not centuries ${ }^{1}$. In addition, since demand for and availability of biological resources are unevenly distributed around the planet, not everyone will be affected equally. Certainly, damaging effects on the integrity of ecosystems, especially because of the extinction of 
species, are already under way at an unsustainable rate, with largely unpredictable but certainly highly damaging effects on human futures ${ }^{20}$.

Economic activities require material inputs, including energy. Given overshoot, these inputs will unavoidably have to be reduced, a process called 'dematerialization'. Such dematerialization, however, will challenge, to different degrees, the continuity of these economic activities. Some activities can be partially dematerialized, but this is less of an option for economic activities in conjunction with poverty eradication. Those activities, which include long-term security in food, energy, water and sanitation infrastructure, and shelter, require more material input to achieve better socioeconomic outcomes because 'poverty eradication' means eliminating poverty forever, or at least for several generations, as defined by the Sustainable Development Goal 1.

We examine the implications for poverty eradication when overshoot (living off the depletion of biological capital) is no longer an option. In that era, humanity's physical metabolism must stem entirely from Earth's biological regeneration.

Conventional development strategies, promoted by key international institutions or leading development economics textbooks ${ }^{21-25}$, are silent on this question. In fact, they tend to largely ignore biological resource constraints despite the vast academic literature from natural sciences about resource-related subjects ${ }^{3,5,18}$. Despite economies' growing resource dependence ${ }^{8,9,26}$, effective resource security strategies are also absent in mainstream economic debates. This is exemplified by the World Economic Forum's prominent annual Global Competitiveness Report, which rates countries' competitiveness using 103 indicators, none of which reflects any aspect of biological resource security ${ }^{27}$.

Overlooking resource conditions in efforts to reduce, and eventually eradicate, poverty may have been acceptable or even reasonable in the past when resource constraints where not a limiting factor, but this assumption no longer holds. The research presented here examines how different populations are exposed to biological resource risks, arguing that ignoring the importance of enhancing resource security of a population undermines their development prospects.

\section{Countries' resource strategies}

For two reasons, this analysis focuses on the country scale. One is data availability: country-level data are the most consistently available for comparisons across the world. Using UN data also removes the potential risk of biased data selection. The second reason is practical: countries, being sovereign, represent the highest level of decision making. Countries operate many powerful levers to steer their trajectories, including managing their currencies, governing taxation, setting regulations, choosing policies and implementing their decisions, for which they have at their disposal not just administrators but also police and military force.

Governments can use policy tools to enhance their countries' resource security by managing both resource demand and resource availability. Largely, however, they do not. For example, global carbon emission time series show increasing trends, with temporary reductions imposed by disasters (first and second oil crisis, 2008 financial crisis, 2020 COVID-19 lockdown), not by design (1992 Climate Framework ${ }^{28}$, 1997 Kyoto Agreement ${ }^{29}$, 2015 Paris Agreement $^{30}, 2016$ Paris Agreement ratification ${ }^{31}$ ). There are noteworthy exceptions, such as Germany, with a slow but steady energy transformation, and Scotland. Both reduced their territorial carbon emissions from 1990 to $2017 / 2018$, by $30 \%$ for the former ${ }^{32}$ and $47 \%$ for the latter ${ }^{33}$.

In the era of global overshoot, a key question is which countries, including their economies, will be able to maintain their resource security. Most countries have underperformed in their efforts to meaningfully increase their resource security. Further, the failure to improve resource security in the short term will compound

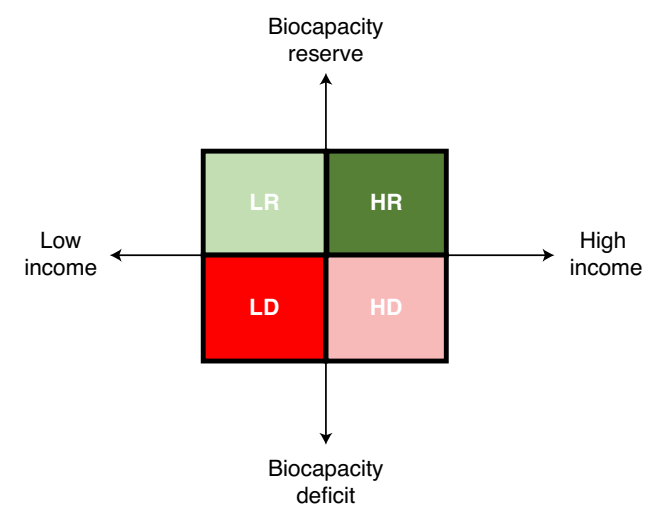

Fig. 1 | Countries are mapped on four quadrants. The dividing line between low and high income is world-average income per person. Clockwise from the top left: $L$ and $R ; H$ and $R ; H$ and $D ;$ and $L$ and D.

future resource challenges. Even under the best scenarios, national and global sustainability transitions face extensive time delays for improving resource security because the lock-in effect of existing infrastructure determines large portions of future production and consumption patterns.

Apart from deliberate resource efficiency strategies, which take years if not decades to achieve, there are two mechanisms for populations to secure sufficient flows of resources within those time frames while avoiding using less (since it would conflict with poverty eradication among lowest-income populations): either a country has sufficient regeneration within its boundaries or it can obtain those regenerated resources, including waste-absorptive services, from somewhere else. 'Having them' means that the biological assets within the country (minus those permanently leased to actors abroad) can continuously provide the demanded biological flows. Obtaining resources from elsewhere is possible through the following means:

- Domestic overuse: take them from the future by overusing a country's own biological assets (here, getting resources from elsewhere does not refer to 'from other spaces' but to 'from other times'-the future)

- International trade: purchase the resource flows from elsewhere (sufficient purchasing power is required)

- Donation: receive resource flows from elsewhere through foreign aid or a charitable gift

- Use of force: appropriate resource flows from elsewhere by force

This study focuses exclusively on international trade. In this analysis, we exclude the other three options for the following reasons.

Domestic overuse is merely a short-term option. It lasts as long as depletion of one's own assets is possible and overuse of global assets (including carbon emissions or fishing in international waters) is permissible. Since the purpose of this assessment is to analyse how countries are impacted by the end of overshoot, and since living off depletion is increasingly less available and exacerbates the resource security of one's own country even more dramatically in the years following overuse, our analysis is not focusing on those transition years.

Donation assumes large-scale redistribution of resources. It could indeed be a powerful mechanism. We exclude it here because there is not much historical evidence to feed expectations for such redistribution. Over the past decades, international redistribution between countries has been small. Exceptions include intra-EU transfers and some favourable fossil fuel exports as in the case of Venezuela supporting Cuba. Otherwise, international redistribution is limited mostly to international development efforts. 


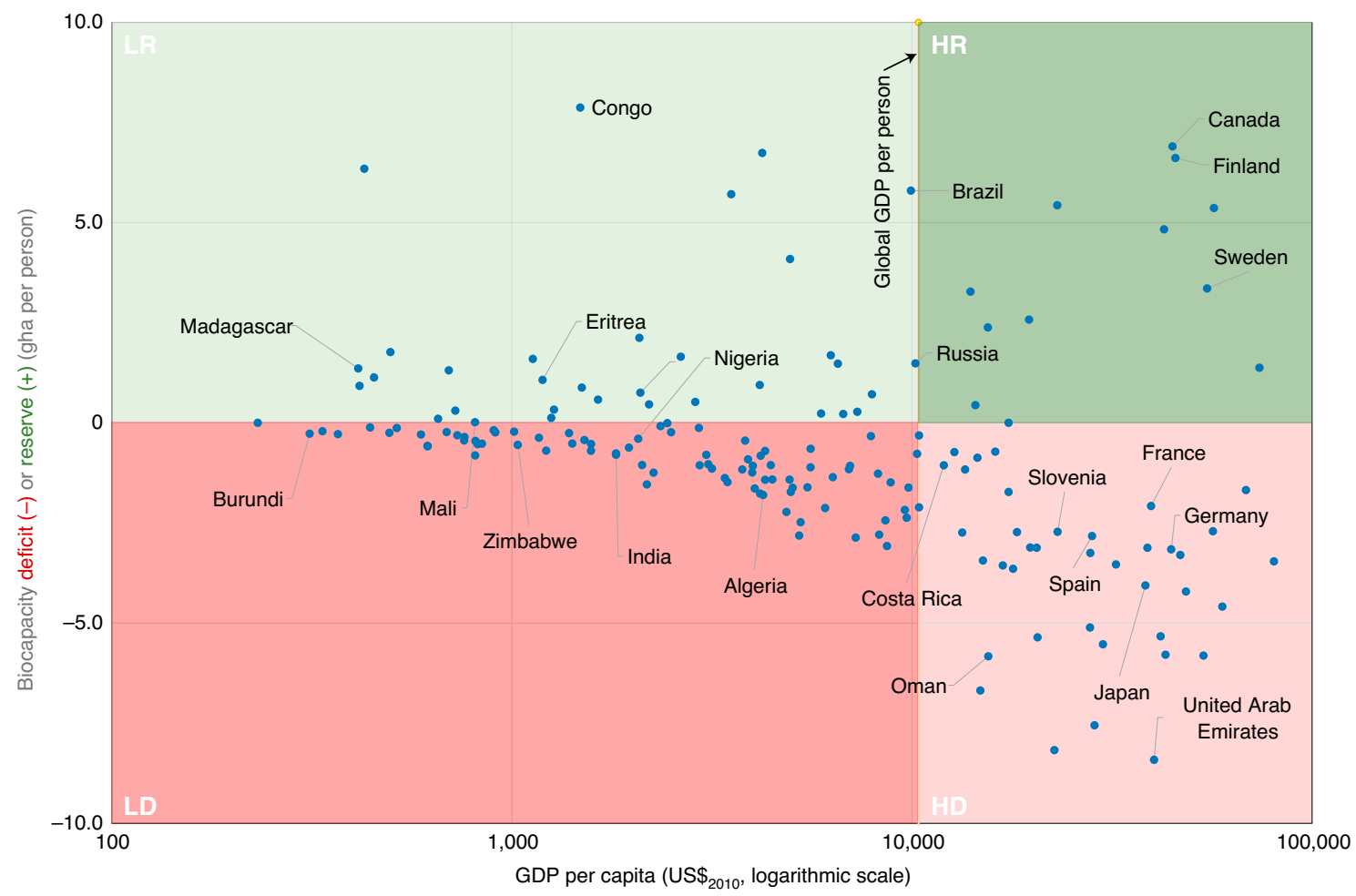

Fig. 2 | Distribution of countries in 2017 across the four quadrants. Note the pattern of biocapacity deficits (per person) of lower-income countries. Lower incomes seem to limit ever more the size of countries' per-person biocapacity deficits. For identifying all countries, consult Supplementary Data 1 (tab: Fig 2 Quadrants).

Only about $5 \%$ of international development efforts (which themselves are about $0.2 \%$ of global gross domestic product (GDP) $)^{34}$ ) have supported biological resource transfers, mainly of food. A big portion of this transfer is handled by the World Food Programme and is linked to extreme emergencies. In the context of increasing global overshoot, all countries will face growing pressure to reduce their material metabolism, making it politically even more challenging to meaningfully increase country-to-country resource transfers. In addition, such redistribution schemes have not come about quickly in the past, apart from sporadic short-term aid during disaster emergencies. Hence, donations are highly unreliable and minute in scale.

Use of force is an unrealistic resource acquisition strategy currently since the cost and risk of warfare, including long-term reputational risks, far exceed the resource benefits secured through use of force. However, formal colonialism has been a powerful mechanism for resource acquisition through the use of force in the past centuries, when a few nations pillaged the vast natural resources of other cultures on a continental scale, with consequences that are still lasting today. Since World War II, there have been few economically successful efforts by countries to permanently access extraterritorial resources by force.

Given these two primary resource access options of owning or purchasing, our research examines countries' exposure to biological resource insecurity by focusing on this central dual challenge: (1) not having sufficient resources within their territory and (2) not having the financial advantage to compensate this resource deficit through their purchasing power. We identify which countries are most exposed. Data in Supplementary Data 1 show also how their situations have changed over time.

The Methods section summarizes how we measure these two conditions: tracking a population's biological resource situation and assessing that population's financial possibilities. A more-detailed methodological description of the resource assessment is available in the Supplementary Information.

The two axes of resource security and purchasing strength. On the basis of domestic resource security and international purchasing strength, all countries can be plotted onto a two-dimensional space. One axis reflects their average annual income (in nominal US\$ per person). The dividing line of this axis is global average GDP per person for 2017 of US $\$_{2010} 10,380^{35}$ per annum (Fig. 1). The other axis shows their biocapacity deficit or reserve (in global hectares per person).

\section{Countries' resource security and income}

To analyse countries' resource security, countries are positioned on the graph according to net domestic biocapacity availability (the difference between a country's biocapacity and its ecological footprint of consumption, measured in global hectares (gha) per person) on the vertical axis, and its per-person GDP $\left(\right.$ US $_{2010}$ ) on the horizontal axis (Fig. 2, as outlined in Fig. 1).

Figure 2 includes all countries for which 2017 data exist, representing over $99 \%$ of the world population. In the low income (L) and biocapacity reserve (R) quadrant (LR), the high income $(\mathrm{H})$ and $(\mathrm{R})$ quadrant $(\mathrm{HR})$, and the $(\mathrm{H})$ and biocapacity deficit $(\mathrm{D})$ quadrant (HD), no patterns between GDP and net biocapacity seem to emerge. The LD quadrant (bottom left), however, shows a distinct relationship: the triangular concentration of countries in the upper right corner of this quadrant seems to indicate that the lower a country's income, the lower its ability to run a biocapacity deficit. One possible interpretation is low incomes within the LD quadrant already act as a constraint, limiting the ability of the country to purchase and consume biocapacity from elsewhere. This may be the main cause limiting their ability to run a larger biocapacity deficit. Higher average incomes, by contrast, seem to enable larger 
Quadrant populations over time (where International Monetary Fund data exist)

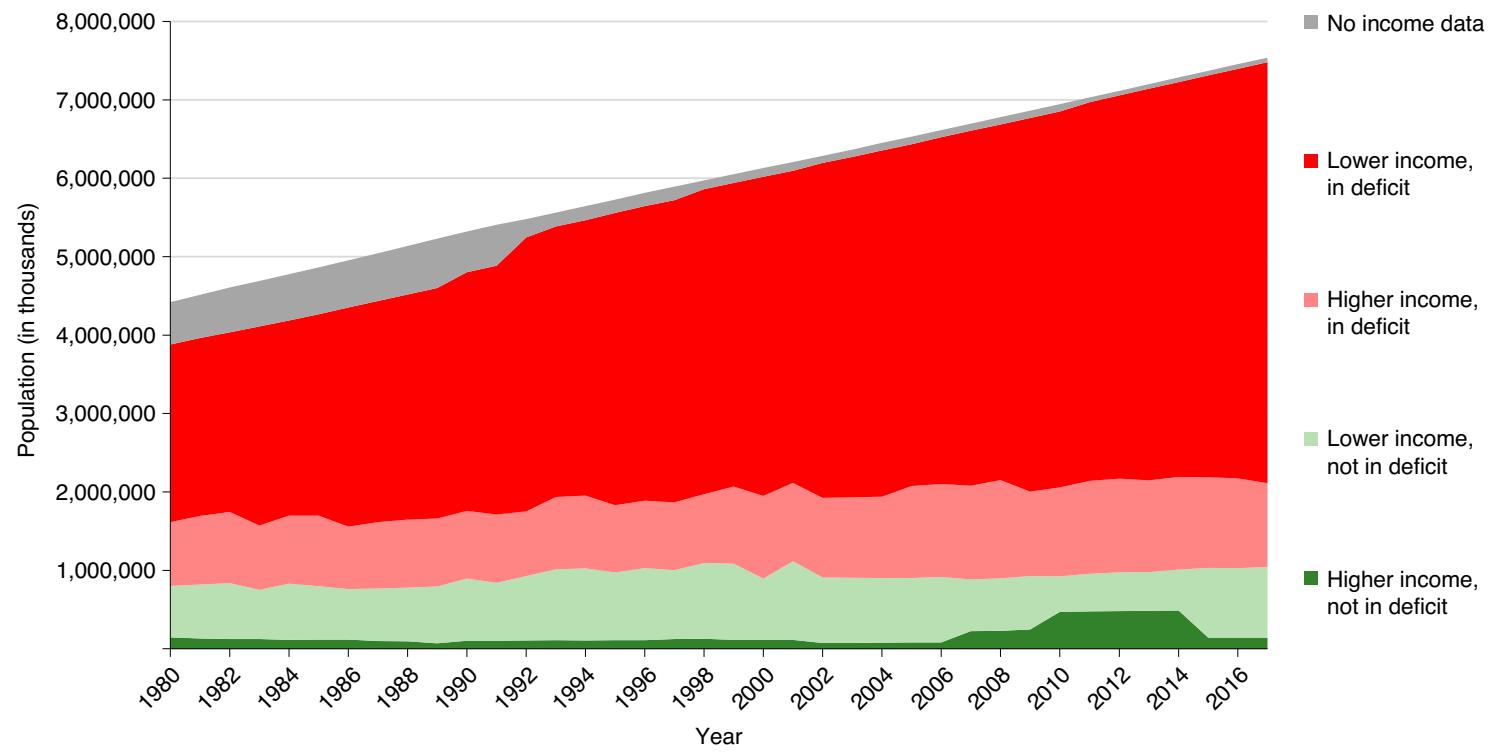

Fig. 3 | The number of people in each biocapacity-income quadrant from 1980 to 2017. The increases in the share of the HR quadrant (higher-income countries with a biocapacity reserve) in 2006 and 2010 reflect Russia and Brazil's rising incomes relative to the world average. Both countries reversed into the LR group in 2015. For details on which countries lie in each quadrant, see Supplementary Data 1 (tab: Fig 1-3-4 Over Time).

biocapacity deficits, and for high-income countries, these deficits seem less determined by income levels as apparent in the right portion of the figure. For example, there are relatively large differences in biocapacity deficits among France, Germany, the Netherlands and Japan, which all have similarly high incomes. These countries have all the financial ability to access biocapacity from outside their national boundaries by net-importing biological resources and by emitting more carbon than their own ecosystems absorb, enabled by their ability to use fossil fuels.

In $2017,2 \%$ of the world population lived in countries in the HR quadrant, $12 \%$ in the LR quadrant, $14 \%$ in the HD quadrant and $72 \%$ in the LD quadrant (Fig. 3 and Table 1). The number of people living in countries with both a biocapacity deficit and below-average income has been increasing steadily from 2.5 billion in 1980 (including estimates for the populations that are unaccounted for due to lack of data) to 5.4 billion in 2017 , displaying a rate of population growth far above the world average.

In 1980 , the LD quadrant represented $57 \%$ of the world population (including estimates of unaccounted populations), when global overshoot was $19 \%$ above the planet's biocapacity. The growth of this quadrant, representing $72 \%$ of the world population in 2017 , has been accompanied by an increase in global overshoot to $73 \%$ of what the planet's ecosystems can renew; that is, humanity used $173 \%$ of the world's biocapacity.

Figure 4 shows how humanity's ecological footprint, its demand for biocapacity, is distributed among the four quadrants, and how this has changed over time. Earth's total biocapacity is shown as a dashed line. The increase in the planet's estimated biocapacity over the past decades is a reflection of growing yields in agriculture, as reported by the Food and Agriculture Organization ${ }^{36}$, while omitting soil loss, diminishing groundwater tables and changing forest productivity since these data are not published with global consistency.

In Fig. 4, the weight of the LD quadrant on the global ecological footprint becomes even more apparent. Collectively, LD countries' demand alone corresponds to $96 \%$ of the planet's biocapacity. By contrast, the HD quadrant, accommodating $14 \%$ of the world population, used $52 \%$ of the planet's biocapacity. Table 1 summarizes the results for all four quadrants.

Table 1 shows that those living in quadrant HD consume resources at $367 \%$ of global biocapacity on a per-capita basis. Another way of saying this is that if all humanity consumed at that level, it would take 3.67 planet Earths to meet our demand. It further reveals that, on average, residents of HR countries use 2.6 (or $352 \% / 134 \%)$ times more than residents of LD countries. It also documents that $72 \%$ of the world population lives in LD countries, which contain only $34 \%$ of the world's biocapacity. Still on average, people in LD countries have an ecological footprint that exceeds global biocapacity per capita by $34 \%$.

Country trends are available in Supplementary Data 1 (tab: Suppl-Fig 2 Country Trends).

\section{Implications for human development}

This analysis reveals a fundamental shift in the determinants of countries' future development successes and their ability to eradicate poverty and famine.

Famines and resources constraints have occurred in recent human history. It has been argued that they were caused mostly by unequal access rather than absolute, physical scarcities ${ }^{37}$. However, the emergence of the Anthropocene may have shifted this dynamic. The Anthropocene is marked by unprecedented global change leading to declining global ecosystem health and rising pollution, consistent with global ecological overshoot ${ }^{1}$. Biocapacity constraints, while previously local and distributional in nature, are now emerging on a global scale as documented here. Therefore, succeeding with poverty eradication will be impossible without a focus on biological resource security.

To clarify, this study does not suggest that economic access has been unimportant, that distributional issues are negligible or that biocapacity constraints have caused poverty. Rather, it shows that biological resource security is becoming a more influential factor, distinct from the past.

As long as biological capital depletion is still an available option for powering our economies, economic impacts of overshoot will 
Table 1 | Population and resource situation for each quadrant in 2017

\begin{tabular}{llllll}
$\begin{array}{l}\text { Quadrant } \\
\text { (in 2017) }\end{array}$ & $\begin{array}{l}\text { Population } \\
\text { (in thousands) }\end{array}$ & \% of population & $\begin{array}{l}\text { \% of planet's biocapacity } \\
\text { they control }\end{array}$ & $\begin{array}{l}\text { \% of Earth's biocapacity } \\
\text { they use }\end{array}$ & $\begin{array}{l}\text { Footprint per person compared } \\
\text { with global biocapacity per person } \\
\text { (\%) }\end{array}$ \\
\hline HR & 142,001 & 2 & 12 & 7 & 352 \\
LR & 900,607 & 12 & 37 & 18 & 153 \\
LD & $5,367,984$ & 72 & 34 & 96 & 134 \\
\hline HD & $1,069,380$ & 14 & 17 & 52 & 367 \\
\hline Total & $\mathbf{7 , 4 7 9 , 9 7 2}$ & $\mathbf{1 0 0}$ & $\mathbf{1 0 0}$ & $\mathbf{1 7 3}$ & $\mathbf{1 7 3}$ \\
\hline
\end{tabular}

The letter codes identify $\mathrm{L}$ and $\mathrm{H}$ on one axis, and $\mathrm{D}$ and $\mathrm{R}$ on the other. Note that 73 million people among the over 7.5 billion people on the planet in 2017 are unaccounted for in this assessment for lack of data. Most of them would be in the LD quadrant.

be masked, even though ecological debt will accumulate further. Beyond that, a decrease of human well-being is ever more likely and will increasingly be driven by the compound risk of biocapacity deficits and below-average income. The countries most exposed are those already in the LD quadrant.

The resource reduction pressures may arrive faster than the speed at which countries can adapt, given the time lags for adjusting both physical infrastructure and the size of human populations. Currently, countries' fossil fuel dependence is incompatible with the Paris Agreement's warming target (Article 2 of ref. ${ }^{30}$ ). Therefore, global decarbonization is necessary for climate stability. The earlier it is accomplished, the less the climate will change, and the more of our planet's biocapacity will remain. But even decarbonized, people will still need energy. Some non-fossil energy sources will require additional biocapacity, potentially aggravating resource security. In addition, more carbon sequestration capacity will be required, potentially competing with other biocapacity demands. The resource security imperative also presents a catch-22: delayed action accentuates the climate and resource crisis, while an immediate and necessary transition deviates current income streams away from consumption and may not be affordable for lower-income segments of society.

Countries with biocapacity deficits and very high incomes (HD quadrant) such as Switzerland may be able to maintain higher levels of consumption as long as their high income shields them from resource insecurity. By contrast, populations of countries with both biocapacity deficits and insufficient income (LD quadrant) such as Niger or Kenya are fragile, as even slight economic downturns or unfavourable weather conditions that temporarily reduce biocapacity could erode food and energy security ${ }^{38}$. Both biocapacity deficits and insufficient income reduce the likelihood of increased resource flows to those populations currently stuck in poverty, however defined.

A growing human population and increasing demand for ever higher consumption levels will make it progressively more difficult for economic actors within individual countries to afford sufficient resources for their economic activities. It may also push those actors into financial debt due to their need to buy resources from elsewhere. This threatens all countries with biocapacity deficits, but especially those with low incomes.

Many countries' economic plans strive to imitate urban finance centres such as Dubai, Switzerland, Hong Kong or Singapore. Rather than focusing on resource security, they rely on strategies reflecting conventional economic growth trajectories that ignore resource constraints. They see the financial successes of these existing centres and take them as evidence in support of their own development plans. However, they miss out on one fundamental question: whether this development strategy is globally replicable.

Pursuing development pathways characterized by a resource demand that is not globally replicable, apart from raising ethical considerations, is risky since not everybody can be above the average.
For example, the economic successes of Dubai, Switzerland, Hong Kong and Singapore are driven largely by their financial service industries. While those industries' direct and domestic natural resource requirements are small, their functioning depends on financing physical operations that have massive resource requirements. Financial services cannot exist in themselves; rather they need to be of service to real, physical value chains. Those chains have invariably large production footprints.

Lack of replicability also emerges on the consumption side. For example, high-income professionals from financial sectors in urban finance centres will use their income to lead materially comfortable lives. Countries in the highest per-person income bracket also are among the countries with the highest per-person resource requirements, often far beyond what can be replicated worldwide. If all people on Earth adopted the average material demand of residents in Dubai, Switzerland, Hong Kong or Singapore, it would take the biocapacity of 5.6, 2.8, 2.9 $9^{39}$ or 3.7 planet Earths, respectively ${ }^{40}$. In a sustainable world, the reasonable goal from an ecological stability perspective might be using no more than half the planet's capacity, as mentioned previously ${ }^{8}$.

If the development patterns of these cities or territories are not replicable, there is only one way for such entities to avoid their own demise: they must be certain that they can financially outcompete everybody else on this planet forever to secure their resource metabolism. Requiring such a strategy to succeed is precarious for regions at any income level.

Life-threatening risks may be higher for lower-income regions. For example, the 2008 euro crisis resulted in Spain's involuntary ecological footprint contraction of about one-third ${ }^{40}$. However, given that Spain's pre-crisis level of consumption was high-among the top 30 per-person footprints in the world-this footprint shrinkage did not lead to famine. Longevity, for example, increased in Spain since $2008^{41}$, even though the footprint remained at two-thirds of the peak. By contrast, such massive, rapid shrinkage would probably be catastrophic for low-income countries where a large portion of the footprint is related to demand for food.

Outlook. Viable options exist to reshape existing infrastructure (cities, power systems, transport networks) as well as to modify population size. These infrastructure stocks shape how people can live and consequently their resource demand. These stocks also change slowly, highlighting the importance of foresight and long-term planning to reach each entity's necessary resource security.

Development strategies that enhance resource security and well-being are not only possible but essential ${ }^{38}$. Plenty of options exist $^{42}$. We group solutions into five overlapping outcome categories ${ }^{38}$, the first on the supply side and the other four on the demand side:

- Planet-enhancing lasting biocapacity through focus on conservation, restoration and regenerative use. Given the rapid erosion 
Quadrant footprints (where International Monetary Fund data exist)

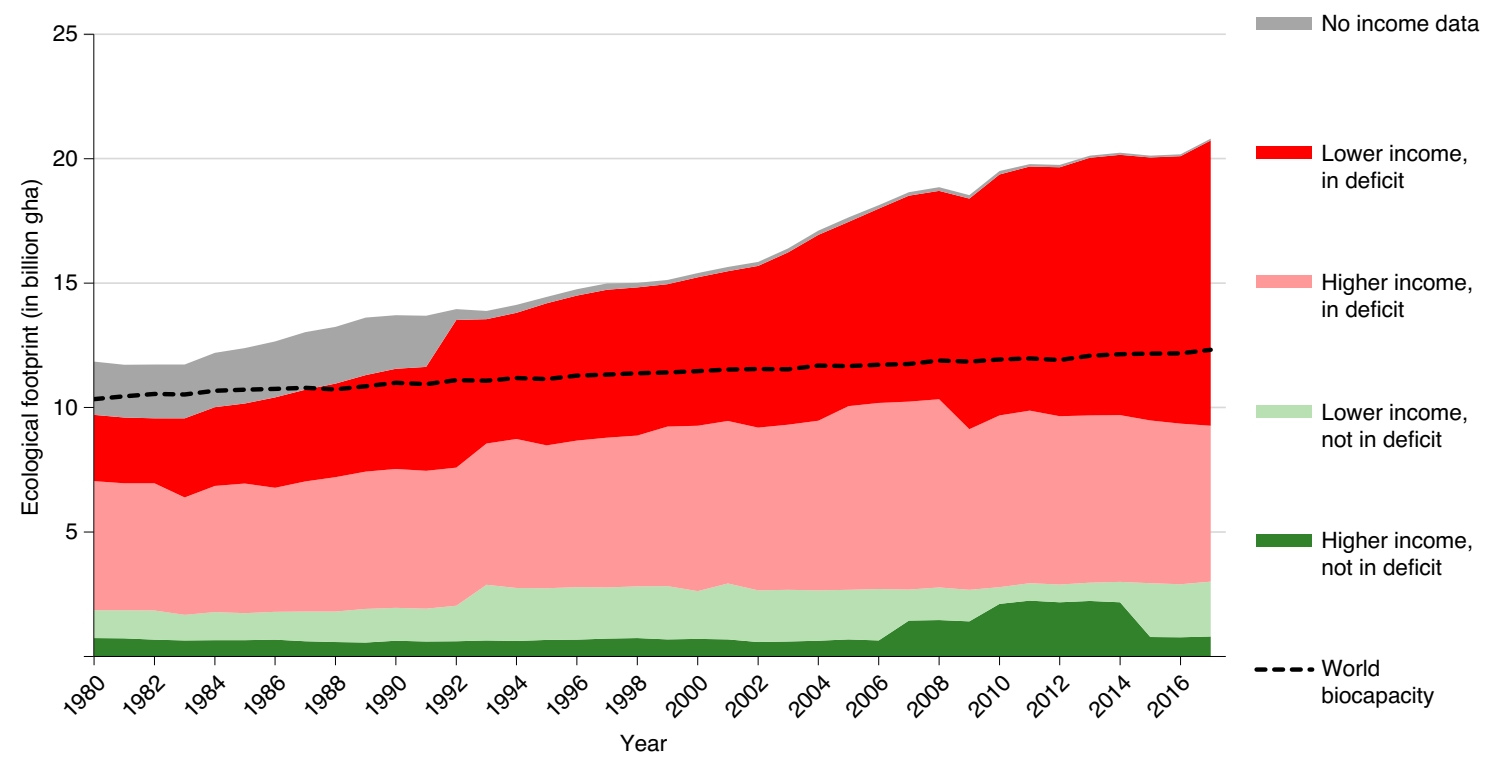

Fig. 4 | The ecological footprint associated with each biocapacity-income quadrant from 1980 to 2017. The total amount of global biocapacity is represented by the dotted line. For details, see Supplementary Data 1 (tab: Fig 1-3-4 Over Time).

of biodiversity and ecosystem health, protecting the health of the biosphere's ecosystems is vital.

- Cities-designing and managing for compact and integrated cities with efficient buildings, which also reduces transport needs.

- Energy-phasing out fossil fuels means replacing them with renewables and boosting efficiency. The land required to absorb the greenhouse gas emissions from fossil energy currently makes up the biggest share of humanity's overall ecological footprint.

- Food-improving production, distribution, and processing. Shifting consumption habits, deemphasizing animal-based products and avoiding food waste offers opportunities. Food demand alone currently occupies roughly 50\% of Earth's biocapacity.

- Population-encouraging smaller families. The number of people sharing the planet determines how much biocapacity is available per person. Enhancing people's lives often also reduces family size, particularly through securing equal rights and opportunities for women and by making safe and affordable family planning available to all.

The persistence of overshoot in the absence of rapid dematerialization makes development strategies that embrace resource security become even more crucial, among both high-income and low-income populations. The finding that $72 \%$ of humanity is currently living in countries challenged by the double curse of a biocapacity deficit and low relative income becomes even more dramatic when recognizing that ecological overshoot is larger than ever. Overshoot's accumulated ecological debt has left the Earth's atmosphere with a carbon concentration in excess of the level needed for a $2{ }^{\circ} \mathrm{C}$ global warming ceiling. This indicates that living off the depletion of natural capital means populations are running out of options and increases the likelihood of ecological poverty traps. Therefore, advancing resource security is turning into an indispensable strategy for eradicating poverty as well as securing development success.

\section{Methods}

This section summarizes how we track a population's biological resource demand and domestic availability. We also explain which income metrics we chose.
A more complete discussion of the resource metric method is included in the Supplementary Methods.

Measuring the biological resource balance. The sustainable development literature has consistently recognized the importance of biological resource security. For example, the foundational Brundtland report expressed it as the need to live "within the planet's ecological means" or "in harmony with the changing productive potential of the ecosystem" ${ }^{43}$.

These principles call for comparing biological resource regeneration with a population's demand on nature. Since people's demands compete for nature's products and services, one way of measuring this relationship between regeneration and human demand is by tracking how much mutually exclusive, biologically productive area is necessary to provide the resource flows that people demand. Humans demand biologically productive areas in several quantifiable ways: production of food, fibre and timber; physical infrastructure such as roads and buildings; and absorption of waste, particularly the carbon dioxide from fossil fuel combustion. The total demand for biologically productive surfaces can be compared with the productive areas available that provide regeneration. Since the productivity of areas varies, they need to be measured not in terms of their physical extension, but in terms of biological regeneration they represent. For example, one can use a biologically productive hectare with world-average productivity as the common measurement unit that then allows expression of both demand and availability of productive areas in units that become comparable across space and time.

Ecological footprint accounting is a well-documented concept to measure the total supply and demand of biological regeneration. In ecological footprint accounting, the ecosystem capacity to regenerate biomass is called biocapacity. It is measured in standardized 'global hectares', which represent the productivity of a world-average biologically productive hectare. The human demand for biocapacity is called the population's 'ecological footprint', and it is the sum of all the mutually exclusive demands on these bioproductive areas. Ecological footprints are also expressed in global hectares.

The principles of ecological footprint accounting, and the derived methods for national and sub-national assessments, are documented extensively within scientific literature ${ }^{6-9,38,44-46}$. The national accounting methodology has also been reviewed and documented by numerous national government agencies ${ }^{47}$.

The essence of the approach is that regeneration is used as the lens to analyse both availability and demand because biological assets are materially the most limiting factor of the human economy ${ }^{1,2}$. In addition, biocapacity and ecological footprint can be tracked and compared with each other on the basis of two principles:

1. By scaling every area proportionally to its biological productivity, each biologically productive area becomes commensurable with any other one. This is the essence of the global hectare.

2. By including only areas that exclude other uses, that is, by making sure that every area is counted only once, the areas can meaningfully be added up, 
both for all the competing demands on productive surfaces (the ecological footprint) and for the surfaces that contain the planet's regenerative capacity (the biocapacity).

The country-level accounts, called the National Footprint and Biocapacity Accounts, show that humanity's demand exceeds Earth's biocapacity, and the gap has been increasing since the $1970 \mathrm{~s}^{8,38,40}$. This is consistent with research on planetary boundaries or ecosystem health ${ }^{1,2,10,11}$.

Countries' resource demand can be analysed from a consumption or a production perspective. The consumption perspective, which is the one used in this study, adjusts for trade and indicates the total resource consumption demand of a population. The production perspective identifies how much demand activities within a country directly put on ecosystems. This could be interpreted as the demand associated with generating the country's GDP.

Countries that demand more than their domestic ecosystems regenerate run a biocapacity deficit. It is made possible by three mechanisms: (1) overuse of domestic ecosystems, or local overshoot; (2) net import of biocapacity; and (3) use of the global commons, as in the case of emitting $\mathrm{CO}_{2}$ from fossil fuel into the atmosphere or fishing international waters ${ }^{38}$.

Global results indicate that as of 2017, Earth had about 12.1 billion biologically productive hectares, according to Food and Agriculture Organization land-use statistics $^{48}$. This includes productive ocean areas. By definition, this equals 12.1 billion global hectares, as each global hectare represents the productive average of all these 12.1 billion hectares. By contrast, human demand in 2017 added up to 20.9 billion global hectares, $73 \%$ higher than the regeneration of all the planet's ecosystems combined (in per-person numbers, an average footprint of 2.8 global hectares contrasted to 1.6 global hectares of biocapacity available per person worldwide). This $73 \%$ overshoot may have dropped to $56 \%$ in 2020 due to lockdowns during COVID-194. In 2017, ecological footprint country averages varied from 0.5 global hectares per person (Eritrea) to 14.7 global hectares per person (Qatar). Biocapacity averages among countries stretch from 0.1 global hectares per person (Singapore) to 84 global hectares per person (Suriname) ${ }^{40}$.

The accounts include only human demands (including domesticated animals) and not those of the millions of other living species, which together make possible the continuous functioning of the global ecosystem. To maintain biodiversity, which is critical for the integrity of the global ecosystem, humanity's footprint would need to be less than the planet's total biocapacity. E.O. Wilson, for example, proposed to only use half the planet's capacity to secure $85 \%$ of its current biodiversity ${ }^{49}$. Using this objective as reference would imply that humanity's current biological metabolism would be three times too large. It also makes clear that zero biocapacity deficits are a necessary but not sufficient condition for planetary resource stability. Still, for simplicity, we use the zero biocapacity deficit line as the demarcation line.

Currently, the single-largest competing demand on the biosphere is the need for carbon sequestration capacity to neutralize emissions from fossil fuel burning. In 2020, this demand made up 57\% of humanity's ecological footprint. To comply with the Paris Agreement's stated goal (Article 2 of ref. ${ }^{30}$ ), this portion of the footprint would need to fall rapidly to zero. This reduction may come at the cost of increasing other parts of the ecological footprint. For example, more forest or agricultural products may be used to substitute for fossil fuels. If the Paris Agreement is fully implemented, there will be legal pressure to eliminate the carbon-related part of the deficit. If it is not implemented, the reduction pressures will emerge more slowly, which will increase the likelihood that the biocapacity will become increasingly damaged by climate change. Taking either path forces a country to eliminate its carbon footprint one way or the other. Fossil fuel dependence is therefore turning into an ever-growing risk. The pressure of increased land use has historically been the leading factor in the extinction of biodiversity, but unless nations can effectively control climate change, it will soon predominate as the major factor responsible for the massive extinction event that we humans have already started as a result of our unsustainable consumption-the sixth such event in the history of our planet.

Measuring ability to purchase resources from abroad. Annual value production of an economy is measured by its GDP. It can be calculated as the value add of all its produced goods and services, as the sum of all the incomes or as the sum of all expenditures. Therefore, GDP can be used as a measure for a country's income ${ }^{50,51}$.

The analysis here focuses on the relative purchasing power of countries' economic actors on global markets. Therefore, we use nominal US\$ (or for time series, constant US\$) instead of purchasing-power-adjusted US\$, which reflect purchasing power on local markets. As economic actors compete for global resources in the same global market, each dollar has approximately the same weight, independent of the dollar's purchasing power in the actor's domestic market (called purchasing power parity). While this simplifies the fact that many commodities do not have a single homogeneous global market, the price range for resources in international markets is much narrower than that between domestic markets.

For the sake of this analysis, we use average country income. Although incomes within countries vary vastly, we assume that nominal per-capita GDP is a reasonable approximation for national purchasing power in international markets. As a medium of exchange, money gives its owner the option to trade it in for physical assets, including biological resources; hence, more money means access to more resources.

Not all international resource transfers are traded on global markets. Purchases could be under the protection of government-to-government arrangements or long-term contracts. The more of the international resource exchanges that occur in global markets, the tighter the competition on the global market for the remaining resources. Such increased competition makes the implications of the analysis presented here even more dramatic.

In the context of global ecological overshoot, biocapacity scarcity will increase; therefore, the competition for purchasing additional resources will become even fiercer. In this case, using world-average income as an approximation for the dividing line between those who can net-purchase from abroad and those who cannot is too lenient. This demarcation indicates only that statistically those above the line can net-purchase from abroad. It does not indicate, however, whether they can purchase enough from abroad to cover their biocapacity deficit. This means that even more national economies than those identified by the $72 \%$ in this paper are excluded from being able to purchase sufficient resources from abroad.

\section{Data availability}

All the data used in the figures are included in Supplementary Data 1. It contains ecological footprint and biocapacity results of most countries, as produced by the National Footprint and Biocapacity Accounts 2021 edition $^{40}$. The income data are also included and stem from the International Monetary Fund ${ }^{52}$.

Received: 24 May 2020; Accepted: 8 March 2021; Published online: 26 April 2021

\section{References}

1. Steffen, W. et al. Planetary boundaries: guiding human development on a changing planet. Science 347, 1259855 (2015).

2. Rockström, J. et al. A safe operating space for humanity. Nature 461, 472-475 (2009).

3. Ecosystems and Human Well-Being: Synthesis (Millennium Ecosystem Assessment, 2005); https://www.millenniumassessment.org/

4. Lin, D., Wambersie, L., Wackernagel, M. \& Hanscom, P. Calculating Earth Overshoot Day 2020: Estimates Point to August 22nd (Global Footprint Network, 2020); https://www.overshootday.org/content/uploads/2020/06/ Earth-Overshoot-Day-2020-Calculation-Research-Report.pdf

5. Meadows, D. H., Meadows, D. L., Randers, J. \& Behrens, W. W. III The Limits to Growth: A Report for the Club of Rome's Project on the Predicament of Mankind (Universe Books, 1972).

6. Wackernagel, M. et al. in Routledge Handbook of Sustainability Indictors (eds Bell, S. \& Morse, S.) 244-264 (Routledge, 2018).

7. Wackernagel, M. et al. in Routledge Handbook of Sustainability Indictors (eds Bell, S. \& Morse, S.) 521-539 (Routledge, 2018).

8. Lin, D. et al. Ecological footprint accounting for countries: updates and results of the national footprint accounts, 2012-2018. Resources 7, 58 (2018).

9. Wackernagel, M. et al. Tracking the ecological overshoot of the human economy. Proc. Natl Acad. Sci. USA 99, 9266-9271 (2002).

10. Regional Assessment Report on Biodiversity and Ecosystem Services for Asia and the Pacific (IPBES, 2018).

11. Regional Assessment Report on Biodiversity and Ecosystem Services for the Americas (IPBES, 2018).

12. Dasgupta, P. The Dasgupta Review: Independent Review on the Economics of Biodiversity-Interim Report (HM Treasury, 2020).

13. IPCC: Summary for Policymakers. In Special Report on Global Warming of $1.5^{\circ} \mathrm{C}$ (eds Masson-Delmotte, V. et al.) (WMO, 2018).

14. Bastin, J.-F. et al. The global tree restoration potential. Science 365 , 76-79 (2019).

15. Gleick, P. \& Palaniappan, M. Peak water limits to freshwater withdrawal and use. Proc. Natl Acad. Sci. USA 107, 11155-11162 (2010).

16. Costello, C. et al. Global fishery prospects under contrasting management regimes. Proc. Natl Acad. Sci. USA 113, 5125-5129 (2016).

17. Butler, J. H. \& Montzka, S. A. The NOAA Annual Greenhouse Gas Index (AGGI) (NOAA, 2020) https://www.esrl.noaa.gov/gmd/aggi/aggi.html

18. IPCC Climate Change 2014: Synthesis Report (eds Core Writing Team, Pachauri, R. K. \& Meyer, L. A.) (IPCC, 2014).

19. Global Energy \& $\mathrm{CO}_{2}$ Status Report: The Latest Trends in Energy and Emissions in 2018 (International Energy Agency, 2019).

20. Bradshaw, C. J. A. et al. Underestimating the challenges of avoiding a ghastly future. Front. Conserv. Sci. 1, 615419 (2021).

21. de Janvry, A. \& Sadoulet, E. Development Economics: Theory and Practice (Routledge, 2016)

22. Roland, G. Development Economics (Pearson, 2014).

23. Taylor, J. E. \& Lybbert, T. J. Essentials of Development Economics (Univ. California Press, 2015).

24. Giugale, M. M. Economic Development: What Everyone Needs to Know (Oxford Univ. Press, 2017) 
25. Collier, P. The Bottom Billion: Why the Poorest Countries Are Failing and What Can Be Done About It (Oxford Univ. Press, 2007).

26. Oberle, B. et al. Global Resources Outlook 2019: Natural Resources for the Future We Want (International Resource Panel, 2019); https://www. resourcepanel.org/reports/global-resources-outlook

27. Schwab, K. The Global Competitiveness Report 2019 (World Economic Forum, 2019); http://www3.weforum.org/docs/WEF TheGlobalCompetitivenessReport2019.pdf

28. United Nations Framework Convention on Climate Change (United Nations, 1992); https://unfccc.int/resource/docs/convkp/conveng.pdf

29. Kyoto Protocol to the United Nations Framework Convention on Climate Change (United Nations, 1997); https://unfccc.int/sites/default/files/resource/ docs/cop3/107a01.pdf

30. UNFCCC Paris Agreement (UN, 2015); https://unfccc.int/sites/default/files/ english_paris_agreement.pdf

31. UNFCCC Paris Agreement - Status of Ratification (UN, 2016); https://unfccc. int/process/the-paris-agreement/status-of-ratification

32. EDGAR - Emissions Database for Global Atmospheric Research: Fossil CO Emissions of All World Countries, 2020 Report (European Commission, 2020); https://edgar.jrc.ec.europa.eu/overview.php? $\mathrm{v}=$ booklet2020

33. Scottish Greenhouse Gas Emissions 2017 (Scottish Government, 2019); https:// www.gov.scot/publications/scottish-greenhouse-gas-emissions-2017/

34. OECD and Donor Countries Working to Focus Development Efforts on COVID-19 Crisis, Building on a Rise in Official Aid in 2019 (OECD, 2020); https://www.oecd.org/development/

oecd-and-donor-countries-working-to-focus-development-efforts-on-covid19-crisis-building-on-a-rise-in-official-aid-in-2019.htm

35. GDP per Capita (Current US\$) (World Bank, 2019); https://data.worldbank. org/indicator/NY.GDP.PCAP.CD?view=chart https://data.worldbank.org/ indicator/NY.GDP.PCAP.CD?view= chart

36. FAOSTAT:Crops (Food and Agriculture Organization, UN, 2021); http://www. fao.org/faostat/en/\#data/QC

37. Drèze, J. \& Sen, A. India: Economic Development and Social Opportunity (Oxford Univ. Press, 1995).

38. Wackernagel, M., Lin, D., Evans, M., Hanscom, L. \& Raven, P. Defying the footprint oracle: implications of country resource trends. Sustainability 11, 2164 (2019).

39. Hong Kong Ecological Footprint Report 2013 (WWF, 2013).

40. National Footprint and Biocapacity Accounts, 2021 Edition (York Univ., Footprint Data Foundation \& Global Footprint Network, 2021); data. footprintnetwork.org

41. 2019 Revision of World Population Prospects (UN Department of Economic and Social Affairs, 2019); https://population.un.org/wpp/

42. Hawken, P. (ed.) Drawdown: The Most Comprehensive Plan Ever Proposed to Reverse Global Warming (Penguin, 2017).

43. World Commission on Environment and Development Our Common Future (Oxford, 1987).

44. Borucke, M. et al. Accounting for demand and supply of the biosphere's regenerative capacity: the national footprint accounts' underlying methodology and framework. Ecol. Indic. 24, 518-533 (2013).
45. Wackernagel, M. \& Beyers, B. Ecological Footprint: Managing the Biocapacity Budget (New Society, 2019).

46. Wackernagel, M. et al. National natural capital accounting with the ecological footprint concept. Ecol. Econ. 29, 375-390 (1999).

47. Country Work (Global Footprint Network, 2020); footprintnetwork.org/ reviews

48. FAOSTAT:Land Cover (Food and Agriculture Organization, UN, 2021); http:// www.fao.org/faostat/en/\#data/LC

49. Wilson, E. O. Half-Earth: Our Planet's Fight for Life (Liveright, 2016).

50. Coyle, D. GDP: A Brief but Affectionate History (Princeton Univ. Press, 2014)

51. Lepenies, P. The Power of a Single Number: A Political History of GDP (Columbia Univ. Press, 2016).

52. World Economic Outlook (WEO) Database (IMF, 2020); https://www.imf.org/ en/Publications/SPROLLS/world-economic-outlook-databases

\section{Acknowledgements}

Projects leading up to this publication, including funding for the National Footprint and Biocapacity Accounts and applications to assessing international development, were funded by MAVA Foundation and Barr Foundation. This particular project did not have dedicated funding and was paid for by unrestricted income of Global Footprint Network. Extra support for preparing this publication was generously provided by Global Footprint Network's present and former board members. We thank P. Dasgupta for his kind review and insightful comments, S. Altiok for her editorial support, L. Wambersie for support in updating the analysis and M. Evans for suggesting the term 'ecological poverty trap. We also gratefully acknowledge the collaboration with York University and the Footprint Data Foundation for their work to maintain and update the National Footprint and Biocapacity Accounts.

\section{Author contributions}

M.W. originated the idea, contributed to research design and led the write-up of the paper. D.L., L.H. and A.M. participated in the research design, research execution and write-up. E.N. performed analytics. P.R. and P.J. contributed to research design and write-up.

\section{Competing interests}

The authors declare no competing interests.

\section{Additional information}

Supplementary information The online version contains supplementary material available at https://doi.org/10.1038/s41893-021-00708-4.

Correspondence and requests for materials should be addressed to M.W.

Peer review information Nature Sustainability thanks Luca Coscieme, Bob Herendeen and the other, anonymous, reviewer(s) for their contribution to the peer review of this work.

Reprints and permissions information is available at www.nature.com/reprints.

Publisher's note Springer Nature remains neutral with regard to jurisdictional claims in published maps and institutional affiliations.

(C) The Author(s), under exclusive licence to Springer Nature Limited 2021 